\title{
DIFFERENZIATED DEGRADATION BY VARIABLE ENVIROMENTAL ESPOSITION: the case study of instrumental diagnostics for Cemetery Church in Messina-Sicily- Italy
}

by A. Bianco

*PAU Dept., University of Reggio Calabria, via Melissari 1-89100 Reggio Calabria, Italy, alessia.bianco@unirc.it

\section{Introduction}

Opportunity to conduct an investigative analysis of monitoring kind, about incidence of conditions of geographic and environmental exposition aimed to realize a conservative evaluation for a ancient or historical building it is not a really common circumstance, if not in systems of laboratorial simulation, using techniques able to define and to control with a good efficacy a lot of thermo-higrometric parameters, but however non capable to describe complexity of real expositive condition. It is ander this point of view that this case history can represent some interesting elements.

\section{Investigation}

This simple research regards an on site diagnostic investigative protocol, projected and made on the Cimitery church of Messina-Sicily-Italy, a large valuable monumental building, realized after the 1908 Messina earthquake using a concrete-bricks mixed technology called confined masonry. The Church is located on top of a hill, it does not present around other buildings or obstacles and for this reason every façade is in the same conditions of natural exposition to sun, wind, rain and above all sea-aerosol, with only one variable, namely a different orientation of façades.

The investigative campaign has seen first of all realization of a dense thermographic mapping for every façade, showing in the North façade, as usually, a perceptible variation of hygrometric content and of thermographic flow. So, it were realized some direct instrumental investigations, finalized to value material and technological conservative conditions of materials, using the SonReb method (ultrasonic investigation and Schmidt hammer test) in peculiar points of reinforced concrete frame and of brick masonry, defining an evident denial of thermographic analysis. In fact both qualitative and quantitative results of material investigation show a particular degradation of the façade positioned in front of sea, that is at same time exposed to sea-aerosol and to strong winds and a better performance of brick in comparison with reinforced concrete, giving some element of evaluation, useful for consequent phase of structural and conservative project (figures 1-3).

\section{Conclusions}

The study concluded considering, for the specific case in object, that: the issue of exposition to sea-aerosol of greater incidence in comparison with the geographic orientation; brick masonry is more lasting then reinforced concrete to sea-aerosol, with some indication of general character about need to realized different investigative analysis for a reciprocal validation and about the complex topic of degradative aggression of environmental factors.

\section{REFERENCES}

[1] Castagneto F., "L'analisi termografica per la diagnosi del degrado degli edifici in muratura riflessioni sullo stato dell'arte", in AAVV, Proceedings of 9 National Congress of AIPND, Padova, 25-27 settembre 1997.

[2] Cianciolo Cosentino G., II Gran Camposanto di Messina, in AA.VV., L'architettura della memoria in Italia. Cimiteri, monumenti e città 1750-1939, pp. 77-91, Skira, Palermo, 2007.

[3] Rosina E., Grinzato E., "Infrared and Thermal Testing for Conservation of Historic Buildings", in; Materials Evaluation, ASNT Journal, Agosto 2001 Columbus (OH) USA. 


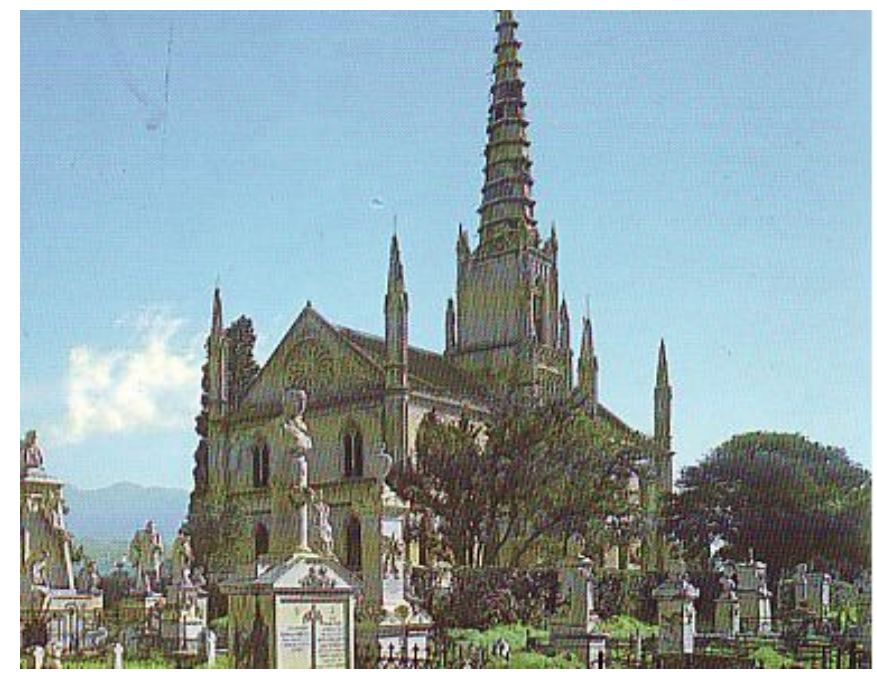

Fig. 1. Cimitery church of Messina, 2010

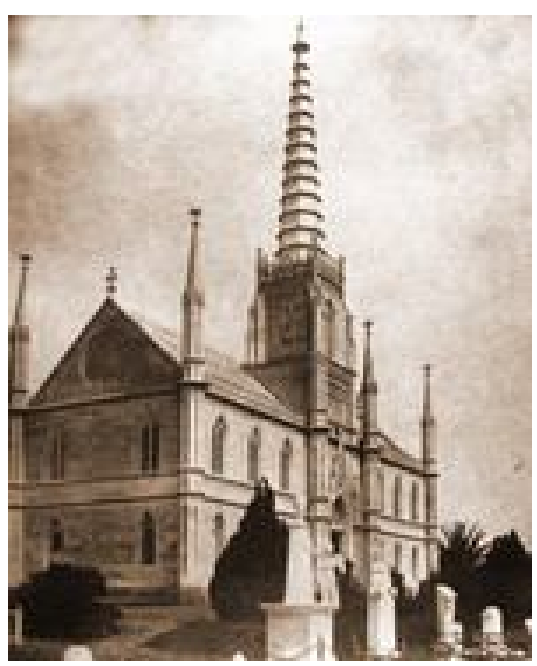

Fig. 2. Cimitery church of Messina, 1923

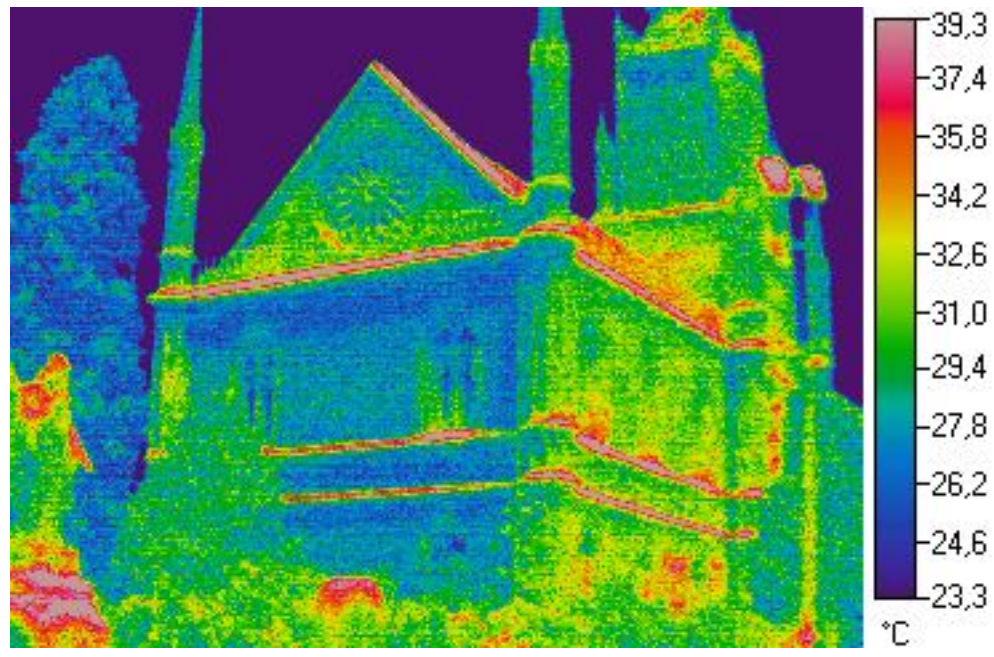

Fig. 3. Cimitery church of Messina, TI investigations 